\title{
Mass spectrometry methods measured androgen and estrogen concentrations during pregnancy and in newborns of mothers with polycystic ovary syndrome
}

\author{
Mirte R Caanen', Esther A Kuijper' ${ }^{1}$, Peter G Hompes', Mark M Kushnir ${ }^{2,3}$, \\ Alan L Rockwood ${ }^{2,3}$, Wayne A Meikle ${ }^{3,4}$, Roy Homburg ${ }^{5}$ and Cornelis B Lambalk ${ }^{1}$ \\ ${ }^{1}$ Division of Reproductive Medicine, Department of Obstetrics and Gynaecology, VU University Medical Center \\ (VUmc), Gebouw Zuid, Amstelveenseweg 601, 1081 JC Amsterdam, The Netherlands, ${ }^{2}$ ARUP Institute for Clinical \\ and Experimental Pathology, Salt Lake City, Utah, USA, ${ }^{3}$ Department of Pathology, University of Utah School of \\ Medicine, Salt Lake City, USA, ${ }^{4}$ Department of Medicine, University of Utah School of Medicine, Salt Lake City, USA \\ and ${ }^{5}$ Homerton Fertility Centre, Homerton University Hospital, London, UK
}

\author{
Correspondence \\ should be addressed \\ to M R Caanen \\ Email \\ m.caanen@vumc.nl
}

\begin{abstract}
Objective: Little is known about the aetiology of polycystic ovary syndrome (PCOS). Some suggest that elevated maternal androgens during gestation play a causative role. This implies placental passage of androgens during pregnancy. The aim of this study is to compare androgen and estrogen concentrations in maternal serum during pregnancy and in umbilical cord blood, between mothers with PCOS and their offspring compared to controls.

Design: Prospective case-control study.

Methods: Maternal blood samples were collected around 20 weeks of gestation and at delivery. Umbilical cord blood was also taken at delivery. Androgens (testosterone (T), androstenedione (ADION), dehydroepiandrostenedione (DHEA)) and estrogens (estrone $\left(E_{1}\right)$, estradiol $\left(E_{2}\right)$, estriol $\left(E_{3}\right)$ ) were measured using the liquid chromatography tandem mass spectrometry (LC-MS/MS) methods.

Results: At 20 weeks of gestation: T $(P=0.019)$ and ADION $(P=0.034)$ were higher in the PCOS mothers (pregnant with a girl), whereas DHEA, $E_{1}, E_{2}$, and $E_{3}$ were not different. Maternal concentration at birth: T $(P=0.004)$ and ADION $(P=0.009)$ were also higher in the subgroup of PCOS mothers that were pregnant with a girl compared to the girl pregnancy controls. DHEA, $E_{1}, E_{2}$ and $E_{3}$ were not different. In umbilical cord blood, no differences were found for T, ADION, DHEA, $E_{2}, E_{3}$, and AMH between the PCOS mothers and the controls respectively. $E_{1}$ was lower in girls from PCOS mothers $(P=0.007)$.

Conclusions: Despite elevated maternal androgen concentrations during pregnancy in PCOS mothers, offspring showed no signs of elevated androgen concentrations in cord blood at birth using the latest highly specific LC-MS/MS methods.

\section{Introduction}

Polycystic ovary syndrome (PCOS) is a common endocrine and metabolic disorder affecting 5-15\% $(1,2,3,4,5)$ of women in their reproductive lifespan according to the criteria used. PCOS is characterized by at least two of the following criteria: oligo- or amenorrhoea, signs of hyperandrogenism (acne, hirsutism and/or biochemical hyperandrogenemia); and/or polycystic ovaries determined by ultrasound (6). The syndrome is associated with fertility problems, an increased risk of insulin resistance (type 2 diabetes) and cardiovascular disease $(1,2)$.

Published by Bioscientifica Ltd. 
PCOS is a complex genetic disease and the phenotype is likely the result of the interplay of variation in a number of different genes with environmental factors. Twin (7) and genetic studies $(8,9,10,11)$ show high heritability of PCOS, and particularly hyperandrogenism (12). The pathophysiology of PCOS is still poorly understood. From animal studies it is known that prenatal exposure to supraphysiological androgen concentrations in mothers leads to PCOS phenotypes in the offspring $(13,14,15)$. In addition, in cultured mice cells, androgens seem to stimulate growth of pre-antral and small follicles. In primate ovaries, androgens seem to enhance FSH receptor-expression $(16,17,18)$. Whether this is the case in humans as well remains debatable.

The testosterone transfer theory suggests that androgens from the male in opposite-sex twins lead to masculinisation of the female co-twin (19). Androgen exposure in opposite-sex twin girls has been associated with reduced fecundity (20). However, Medland et al. (21) could not confirm this theory based on their observations. Furthermore, the prevalence of PCOS is not different in girls from opposite-sex compared to dizygotic girl-girl twins (22).

In relation to androgens in PCOS, the question remains whether prenatal exposure to androgens could cause PCOS and even more importantly can maternally elevated androgens play a role? There are studies that suggest that maternal androgens from PCOS women are passed on to their offspring during gestation trough placental passage and could possibly contribute to higher androgen concentrations during gestation and at birth in PCOS offspring. Others speculate that more androgens are synthesized endogenously by the fetus of PCOS offspring $(12,23,24,25,26)$. The aim of our study is to compare androgen and estrogen concentrations in maternal serum during gestation and in umbilical cord blood, between mothers with PCOS and their offspring compared to non-PCOS mothers and their offspring, using highly specific liquid chromatography tandem mass spectrometry (LC-MS/MS) methods.

\section{Subjects and methods}

\section{The study population}

Subjects were part of a large prospective cohort study that aimed to compare perinatal reproductive endocrinology in singleton vs twin pregnancies (27), performed between 2004 and 2009. Maternal reproductive hormones were measured during pregnancy as well as at time of delivery and from the neonates in umbilical cord blood. We identified 20 PCOS mothers and 83 matched controls. PCOS was diagnosed according to the Rotterdam criteria (4). Clinical signs of hyperandrogenism were assessed by the presence of hirsutism (FerrimanGallwey score >8) (28) and/or acne. The controls were women pregnant after natural conception who had a regular menstrual cycle ( $<35$ days) and no signs of androgen excess (hirsutism and/or acne). Controls were matched by age, parity and gestational age at delivery. The study was approved by the VU Medical Center ethical committee and written informed consent was obtained from all participants.

\section{Blood samples}

Maternal venous serum samples were taken around 20 weeks (18-22 weeks) of gestation and during labour. Umbilical cord blood was sampled immediately after delivery of the placenta (mixed arterial and venous blood). Blood samples were centrifuged (for $10 \mathrm{~min}$, 3000 revolutions/min) and stored at $-20{ }^{\circ} \mathrm{C}$ degrees.

Samples were analysed for estrogens (estrone $\left(\mathrm{E}_{1}\right)$, estradiol $\left(\mathrm{E}_{2}\right)$, and estriol $\left(\mathrm{E}_{3}\right)$ ) and androgens (testosterone (T), androstenedione (ADION), and dehydroepiandrostenedione (DHEA)) using the LC-MS/MS methods at ARUP Laboratories (Salt Lake City, UT, USA). Samples were transported to ARUP Laboratories on dry ice. $\mathrm{T}, \mathrm{E}_{1}, \mathrm{E}_{2}, \mathrm{E}_{3}$, hydroxylamine, formic acid, trifluoroacetic acid, dansyl chloride and sodium carbonate were purchased from Sigma Aldrich. ADION, DHEA were purchased from Steraloids, Inc. (Newport, RI, USA). The internal standards were deuterium labeled analogs of the steroids; $\mathrm{d}_{3}$-Te was purchased from Cambridge Isotope Laboratories (Andover, MA, USA); $\mathrm{d}_{4}-\mathrm{E}_{1}, \mathrm{~d}_{3}-\mathrm{E}_{2}$, $d_{3}-E_{3} d_{7}$-ADION and $d_{2}$-DHEA were purchased from CDN Isotopes (Toronto, ON, USA). All other chemicals were of the highest purity commercially available. Samples were analyzed using the liquid chromatography tandem mass spectrometry methods (LC-MS/MS) as previously described $(29,30,31,32)$. Briefly, steroids were extracted from the samples. DHEA, ADION and T were derivatized with hydroxylamine to form oxime derivatives and $\mathrm{E}_{1}, \mathrm{E}_{2}$ and $\mathrm{E}_{3}$ were derivatized with dansyl chloride to form dansyl derivatives $(29,32)$. The lower limit of quantification (LOQ) for estrogens $\left(E_{1}, E_{2}\right.$ and $\left.E_{3}\right)$ was $1 \mathrm{pg} / \mathrm{ml}$, for DHEA $0.05 \mathrm{ng} / \mathrm{ml}$ and $0.01 \mathrm{ng} / \mathrm{ml}$ for testosterone and ADION. The intra- and inter-assay coefficients of variation $(\mathrm{CV})$ were $<8 \%$ and $<11 \%$ respectively. All steroids were analyzed in positive ion mode using electrospray ion source on a triple quadruple mass spectrometer (API4000; 
AB Sciex, Foster City, CA, USA). The HPLC system consisted of series 1260 HPLC pumps (Agilent Technologies, Santa Clara, CA, USA) and a HTC PAL autosampler (LEAP Technologies, Carrboro, NC, USA) equipped with a fast wash station. The quadrupoles Q1 and Q3 were tuned to unit resolution and the mass spectrometer conditions were optimized for maximum signal intensity of each steroid. Two mass transitions were monitored for each steroid and its internal standard (33). Quantitative data analysis was performed using Analyst 1.5.2 Software (AB/Sciex, Concord, Ontario, Canada). Calibration curves were generated with every set of samples using six calibrators and three quality control samples were included with every set of samples. Specificity of the analysis for each steroid in every sample was evaluated by comparing concentrations determined using the primary and the secondary mass transitions of each steroid and its internal standard.

Anti-Müllerian Hormone (AMH) was measured using GEN II AMH elisa (Beckman Coulter) with a lower limit of detection of $0.2 \mu \mathrm{g} / \mathrm{l}$ (intra-assay CV: $7-10 \%$, inter-assay CV: $8 \%)$.

\section{Statistical analysis}

All statistical procedures were performed using SPSS version 20.0 (SPSS, Inc.). Baseline characteristics are reported as means ( \pm s.D.) or number (percentages). Independent samples $t$-tests and $\chi^{2}$-tests were performed to compare baseline characteristics. Hormone concentrations are reported as mean ( \pm s.D.) and the nonparametric Mann-Whitney test was performed to compare the data. Hormone concentrations were positively skewed and therefore logarithmically transformed data were used for the regression analyses. Linear regression analyses were conducted to compare hormone concentrations between the mothers with and without PCOS. Data were corrected for age, BMI, parity, smoking and mode of delivery. A $P$ value of $<0.05$ was considered significant.

\section{Results}

Maternal and neonatal baseline characteristics are shown in Table 1.

Concerning the mothers: age, BMI at 20 weeks of gestation, age of menarche, time trying to conceive, ethnicity, smoking status, parity and mode of delivery did not differ between the groups. However, by definition and as a result of our study design cycle duration, mode of conception, acne and signs of hirsutism differed
Table 1 Baseline characteristics. Data are presented as mean ( \pm s.D.) or number (percentages) of the group.

\begin{tabular}{|c|c|c|c|}
\hline Characteristics & $P \cos (n=20)$ & $\begin{array}{c}\text { Non-PCOS } \\
\quad(n=83)\end{array}$ & $P$ value \\
\hline \multicolumn{4}{|l|}{ Mother } \\
\hline Age (years) & $32.0(4.0)$ & 33.8 (3.9) & 0.061 \\
\hline Cycle duration (days) & $140.1(132.8)$ & $27.7(2.9)$ & $0.002 *$ \\
\hline BMI $\left(\mathrm{kg} / \mathrm{m}^{2}\right)^{\mathrm{a}}$ & 24.2 (3.6) & $25.1(4.0)$ & 0.375 \\
\hline $\begin{array}{l}\text { Age of menarche } \\
\text { (years) }\end{array}$ & $13.3(2.0)$ & $13.3(1.6)$ & 0.911 \\
\hline $\begin{array}{l}\text { Time trying to conceive } \\
\text { (months) }\end{array}$ & $8.3(9.0)$ & $7(13.0)$ & 0.698 \\
\hline Mode of conception & & & $0.000 *$ \\
\hline Natural & $5(25 \%)$ & $83(100 \%)$ & \\
\hline Ovulation induction & $11(55 \%)$ & 0 & \\
\hline IVF & $1(5 \%)$ & 0 & \\
\hline ICSI & $3(15 \%)$ & 0 & \\
\hline Ethnicity & & & 0.784 \\
\hline Caucasian & $18(90 \%)$ & $73(88 \%)$ & \\
\hline Asian & & $1(1.2 \%)$ & \\
\hline Mediterranean & $2(10 \%)$ & $4(4.8 \%)$ & \\
\hline Creole & & $4(4.8 \%)$ & \\
\hline Other & & $1(1.2 \%)$ & \\
\hline Acne & & & $0.000 *$ \\
\hline Yes & $11(55 \%)$ & 0 & \\
\hline No & $9(45 \%)$ & $83(100 \%)$ & \\
\hline Hirsutism & & & $0.000 *$ \\
\hline Yes & $12(60 \%)$ & 0 & \\
\hline No & $8(40 \%)$ & $83(100 \%)$ & \\
\hline Smoking & & & 0.216 \\
\hline Yes & $9(45 \%)$ & $51(61.4 \%)$ & \\
\hline No & $11(55 \%)$ & $32(38.6 \%)$ & \\
\hline Para & & & 0.051 \\
\hline 0 & $6(30 \%)$ & $33(39.8 \%)$ & \\
\hline 1 & $13(65 \%)$ & $31(37.3 \%)$ & \\
\hline$>1$ & $1(5 \%)$ & $19(22.9 \%)$ & \\
\hline Mode of delivery & & & 0.492 \\
\hline Natural & $14(70 \%)$ & $52(62.7 \%)$ & \\
\hline Assisted delivery ${ }^{b}$ & $6(30 \%)$ & $31(37.3 \%)$ & \\
\hline \multicolumn{4}{|l|}{ Offspring } \\
\hline Neonatal sex & & & 0.052 \\
\hline Girl & $14(70 \%)$ & $38(45.8 \%)$ & \\
\hline Boy & $6(30 \%)$ & $45(54.2 \%)$ & \\
\hline $\begin{array}{l}\text { Gestational age at } \\
\text { birth (weeks + days) }\end{array}$ & $39+6(3)$ & $39+4(2)$ & 0.652 \\
\hline Birth weight (grams) & $3552(451)$ & $3410(649)$ & 0.385 \\
\hline
\end{tabular}

$n$, number of subjects; *indicates a significant difference. ${ }^{a} B M I$ at 20 weeks of gestation.

${ }^{\mathrm{b}}$ Assisted delivery includes: cesarean section and ventouse delivery.

significantly between the groups. Ninety percent of the cases demonstrated clinical and/or biochemical signs of hyperandrogenism (45\% of the cases clinical and biochemical signs of hyperandrogenism, 40\% clinical signs (acne and/or hirsutism), 5\% biochemical, 10\% none). Most of the women were multiparae and of Caucasian origin. Concerning the offspring: remarkably $70 \%$ of the offspring in the PCOS group were girls vs $45.8 \%$ in the 
control group $(P=0.052)$, whereas gestational age at birth and birth weight did not differ between the groups.

\section{Mean hormone concentrations}

The mean hormone concentrations in maternal serum (mid-gestation and delivery) and cord blood, according to maternal PCOS status, according to fetal gender are reported in Table 2 .

Non-parametric Mann-Whitney test showed similar results compared to the regression analyses; 20 weeks of gestation, pregnant with a girl: $\mathrm{T}(P=0.059), \mathrm{ADION}$ $(P=0.026)$, at delivery $\mathrm{T}(P=0.003)$ ADION $(P=0.005)$, umbilical cord $\mathrm{T}(P=0.31)$, ADION $(P=0.057), \mathrm{E}_{1}$ $(P=0.007)$. Regression analyses were performed to rule out confounding.

\section{Regression analyses}

Linear regression analyses according to fetal gender were conducted with hormone concentrations used in the model as dependent variables and PCOS/non-PCOS as the independent variable (Table 2 ). The model was tested with age, BMI, smoking, parity and mode of delivery as possible confounders.

\section{Maternal serum mid-gestation}

Around 20 weeks of gestation PCOS mothers pregnant with a girl have significantly higher $\mathrm{ADION}$ and $\mathrm{T}$ concentrations compared to non-PCOS mothers pregnant with a girl. In boys ADION and $\mathrm{T}$ also tend to be higher.

\section{Maternal serum at delivery}

In accordance to mid-gestational concentrations, PCOS mothers pregnant with a girl show significantly higher ADION and T concentrations compared to the non-PCOS mothers. However, $\mathrm{E}_{1}$ was significantly higher in the PCOS mothers pregnant with a boy, ADION and $\mathrm{T}$ tend to be higher.

\section{Cord blood}

Androgens in cord blood did not differ significantly between daughters from the PCOS and the non-PCOS mothers. $\mathrm{E}_{1}$ was significantly lower in girls from the PCOS mothers and $\mathrm{E}_{2}$ also tends to be lower. Cord blood from boys showed comparable estrogen and androgen concentrations between the PCOS and the non-PCOS mothers. Concentrations of $\mathrm{AMH}$ in girls and boys did not differ between the PCOS and the non-PCOS group.

Table 2 Mean hormone concentrations according to fetal gender. Hormone concentrations at 20 weeks of gestation and delivery in maternal serum and in cord blood, according to fetal gender and PCOS status of the mother. Data are presented as mean ( \pm s.D.).

\begin{tabular}{|c|c|c|c|c|c|c|c|c|}
\hline & \multicolumn{4}{|c|}{ Girls $(n=52)$} & \multicolumn{4}{|c|}{ Boys $(n=51)$} \\
\hline & $\operatorname{PCOS}(n=14)$ & Non-PCOS $(n=38)$ & $\beta$ & $P$ value & $\operatorname{PCOS}(n=6)$ & Non-PCOS $(n=45)$ & $\beta$ & $P$ value \\
\hline \multicolumn{9}{|c|}{ Mother mid-gestation } \\
\hline$E_{1}(p g / m l)$ & $3889.3(1565)$ & $4469.4(2513)$ & -0.017 & 0.928 & $5433.3(2823)$ & 3728.7 (2079) & 0.319 & 0.061 \\
\hline$E_{2}(p g / m l)$ & 6441.4 (1909) & $6942.2(3833)$ & -0.113 & 0.559 & $7250(2441)$ & $6074.4(2105)$ & 0.158 & 0.300 \\
\hline$E_{3}(p g / m l)$ & $2213.6(491)$ & $2106.2(628)$ & -0.042 & 0.815 & $2345(458)$ & $1972.9(627)$ & 0.232 & 0.139 \\
\hline ADION (ng/ml) & $2.13(1.49)$ & $1.08(0.43)$ & 0.365 & $0.034 *$ & $2.60(2.67)$ & $1.24(0.81)$ & 0.298 & 0.084 \\
\hline DHEA (ng/ml) & $3.12(1.44)$ & $2.76(1.25)$ & 0.048 & 0.788 & $4.18(4.79)$ & $2.58(1.3)$ & 0.071 & 0.654 \\
\hline $\mathrm{T}(\mathrm{ng} / \mathrm{ml})$ & $1.04(0.80)$ & $0.51(0.22)$ & 0.391 & $0.019 *$ & $1.15(1.04)$ & $0.56(0.32)$ & 0.279 & 0.113 \\
\hline \multicolumn{9}{|l|}{ Mother delivery } \\
\hline $\mathrm{E}_{1}(\mathrm{pg} / \mathrm{ml})$ & $9786.7(6111)$ & $8845.3(6929)$ & 0.074 & 0.690 & $13625(3754)$ & 7454.5 (4834) & 0.500 & $0.015^{*}$ \\
\hline $\mathrm{E}_{2}(\mathrm{pg} / \mathrm{ml})$ & $8184.8(6628)$ & $9882.3(6884)$ & -0.005 & 0.979 & $13850(11036)$ & $9460.0(7084)$ & 0.250 & 0.208 \\
\hline $\mathrm{E}_{3}(\mathrm{pg} / \mathrm{ml})$ & $2342.3(3034)$ & $4392.9(4248)$ & -0.130 & 0.461 & $19922.3(26786)$ & 7843.4 (15971) & 0.182 & 0.341 \\
\hline ADION (ng/ml) & $4.22(3.17)$ & $1.62(0.71)$ & 0.513 & $0.009 *$ & $4.48(5.12)$ & $2.04(1.7)$ & 0.112 & 0.537 \\
\hline DHEA (ng/ml) & $9.11(7.70)$ & $6.85(3.76)$ & 0.199 & 0.360 & $5.16(4.81)$ & $6.09(5)$ & 0.014 & 0.940 \\
\hline $\mathrm{T}(\mathrm{ng} / \mathrm{ml})$ & $2.80(2.32)$ & $0.91(0.64)$ & 0.523 & $0.004 *$ & $2.57(2.83)$ & $1.10(0.9)$ & 0.078 & 0.675 \\
\hline \multicolumn{9}{|l|}{ Cord blood } \\
\hline $\mathrm{E}_{1}(\mathrm{pg} / \mathrm{ml})$ & $10511.1(5717)$ & 22025.7 (12366) & -0.552 & $0.007 *$ & 14734.5 (7707) & 21123.9 (13559) & -0.065 & 0.718 \\
\hline$E_{2}(p g / m l)$ & $5426.1(2334)$ & $8919.2(5373)$ & -0.407 & 0.052 & $9601.5(5044)$ & $9196.4(6586)$ & 0.095 & 0.520 \\
\hline $\mathrm{E}_{3}(\mathrm{pg} / \mathrm{ml})$ & 57412.1 (19263) & $52729.2(22145)$ & -0.041 & 0.836 & $51568(10952)$ & $55135.1(24036)$ & 0.160 & 0.378 \\
\hline ADION (ng/ml) & $0.45(0.25)$ & $0.84(1.11)$ & -0.374 & 0.094 & $0.49(0.17)$ & $0.54(0.25)$ & 0.036 & 0.834 \\
\hline DHEA (ng/ml) & $4.90(2.84)$ & $5.65(6.33)$ & 0.123 & 0.577 & $2.98(0.85)$ & $2.9(2.5)$ & 0.255 & 0.162 \\
\hline $\mathrm{T}(\mathrm{ng} / \mathrm{ml})$ & $0.12(0.04)$ & $0.15(0.21)$ & -0.010 & 0.959 & $0.18(0.07)$ & $0.20(0.12)$ & -0.091 & 0.676 \\
\hline $\mathrm{AMH}(\mu \mathrm{g} / \mathrm{l})$ & $2.11(2.42)$ & $1.26(1.16)$ & 0.178 & 0.412 & $46.8(21.5)$ & 44.31 (30.9) & 0.013 & 0.947 \\
\hline
\end{tabular}

$\beta$ indicates the regression coefficient and *indicates a statistically significant difference between PCOS and non-PCOS mothers. 


\section{Discussion}

In this study, we have demonstrated that maternal hormone concentrations of ADION and T are significantly higher throughout pregnancy (mid-gestation and delivery) in PCOS mothers pregnant with a girl compared to non-PCOS mothers.

Remarkably, although the mothers had elevated concentrations of androgens throughout gestation, daughters of PCOS mothers showed no signs of increased androgen concentrations in umbilical cord blood at birth.

Our data do support less the idea that elevated concentrations of androgens in PCOS-mothers affect offspring, also that offspring themselves have increased production of androgens. This challenges data that support that a maternal hyperandrogenic environment in PCOS-mothers contributes to PCOS features in their daughters other than on the genetic basis according to animal studies.

Animal studies suggest that high maternal androgen concentrations during gestation result in PCOS-like phenotypes, in primates $(14,15,34)$, sheep (35) and rodents (36). Especially studies by Abbott (13, 14, 15, 34, 37), in prenatally exposed rhesus monkeys, have strongly encouraged the hypothesis that the intra-uterine exposure to androgens can cause clinical and biochemical features of PCOS in later life, though these androgen concentrations are supraphysiological.

However, human data are scarce. Pathological conditions in humans that cause hyperandrogenism, for example, congenital adrenal hyperplasia (38) and studies in transsexual women treated with high doses of testosterone $(39,40,41,42)$ show conflicting outcomes.

The present and previous studies $(43,44,45,46)$ show that elevated androgen concentrations during pregnancy in PCOS women, do not contribute to elevated androgens in cord blood. Remarkably, Anderson and Maliqueo, as we did, also found significantly lower ADION concentrations in cord blood of female offspring of the PCOS women, as compared to the female offspring of non-PCOS women $(43,45)$. To our knowledge only Barry et al. (47) reported elevated $\mathrm{T}$ concentrations in cord blood in PCOS daughters compared to controls. Hickey et al. (44) even found no evidence for a relationship between prenatal androgen exposure and PCOS in adolescence in normal pregnancies in a large prospective cohort study. Therefore this study and previous studies fail to support the hypothesis that maternal androgen excess contributes to elevated androgen concentrations in cord blood, and therefore the development of PCOS. Although having close genomic and phenotypic similarity to humans, primates cannot serve as a correct model for the human situation.

During pregnancy maternal androgen excess is unlikely to affect the fetus, because the placenta presents an effective barrier. Placental aromatase rapidly catalyzes the conversion of ADION to $\mathrm{E}_{1}, 16$-hydroxytestosterone to $\mathrm{E}_{3}$ and $\mathrm{T}$ to $\mathrm{E}_{2}$ (4448). A recent study aimed to evaluate the

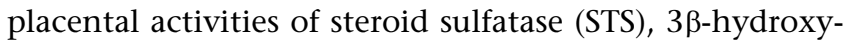
steroid dehydrogenase type 1 (3ß-HSD-1) and P450 aromatase (P450arom) in PCOS compared to normal pregnant women. The data suggest that placental tissue from women with PCOS shows changes in the activities of two important enzymes for steroid synthesis: higher $3 \beta$-HSD-1 and lower P450arom which would indicate increased androgen production during pregnancy (45). In line with our findings, Maliqueo et al. (45) found that cord blood of the female offspring from the PCOS mothers did not contain elevated androgens, and even had lower ADION and higher $\mathrm{E}_{3}$ concentrations (although androgens during pregnancy were elevated). It remains unclear whether placental steroidogenesis is altered in PCOS.

Interestingly, $\mathrm{E}_{1}$ concentrations differ between PCOS and non-PCOS women and in their offspring as well. $\mathrm{E}_{1}$ concentrations at birth were significantly higher in PCOS mothers pregnant with a boy compared to controls. In the women pregnant with a girl, they were also higher but non-significantly. However, cord blood $\mathrm{E}_{1}$ concentrations were lower in daughters of the PCOS women. Limited data are available on $\mathrm{E}_{1}$ concentrations during gestation $(27,49)$ and post-partum. Data by Troisi et al. $(50,51,52)$ demonstrated no gender related differences. Concentrations of $E_{1}$ in cord blood did not differ between boys and girls $(51,52)$. However these data did not report on hyperandrogenism or PCOS prevalence in the mothers. Remarkably Maliqueo et al. also found lower $\mathrm{E}_{1}$ concentrations in PCOS cord blood from daughters compared to controls $(P=0.061)$. It is possible that placental steroidogenesis follows different pathways in PCOS mothers which result in a different ratio of estrogen fractions during gestation and in their offspring (45).

Due to the different phenotypes of women with PCOS, not all mothers had biochemically proven hyperandrogenism, which could influence our results. However, 90\% of the mothers did have biochemical and/or clinical signs of hyperandrogenism. Furthermore, PCOS mothers had higher androgen concentrations throughout pregnancy, which did not lead to higher androgens in cord blood. This suggests that maternal androgens are not transferred directly to their offspring and challenges the hypothesis that maternal androgens directly cause PCOS in their 
daughters. Androgens might have their effect on PCOS offspring in a more indirect manner such as fetal programming. This is in line with twin $(7,22)$ and genetic $(8,9,10,11)$ studies that demonstrate high heritability of PCOS and particularly hyperandrogenism (12).

Furthermore, it remains questionable how closely cord blood reflects actual fetal androgen exposure during gestation (53). Androgens in girls could have been elevated during gestation and could have decreased at the time of birth resulting in normal androgen concentrations in cord blood. Although maternal hormones are almost unable to pass the placenta (54) or are metabolized along the way, it is not clear to what extent maternal androgens programme the fetus for future endogenous androgen biosynthesis.

Collected cord blood was mixed arterial and venous blood, which was inevitable because of the amount of hormones measured. Although there are indications that concentrations differ between arterial and venous cord blood samples $(55,56)$, there is sufficient data that measurements in mixed cord blood do not differ significantly $(27,57)$.

Despite these limitations, this study provides a complete overview of steroid hormone concentrations during gestation and in cord blood of the PCOS vs non-PCOS mothers. Concentrations of estrogens and androgens in this study were determined using highly specific LC-MS/MS methods, a technique that is considered state of the art for measurement of endogenous steroids $(58,59,60,61)$.

\section{Conclusion}

In conclusion, we found that daughters of PCOS mothers do not have elevated concentrations of androgens in cord blood despite the fact that their mothers had elevated serum androgen concentrations throughout gestation. This challenges the idea that a maternal hyperandrogenic environment in PCOS-mothers directly contributes to PCOS features in their offspring. Androgen exposure could, however, play a role in programming the fetus for endogenous androgen production later in life.

\section{Declaration of interest}

The authors declare that there is no conflict of interest that could be perceived as prejudicing the impartiality of the research reported.

\section{Funding}

This research did not receive any specific grant from any funding agency in het commercial, public or non-for-profit sector.

\section{Acknowledgements}

The authors express their gratitude to the women who took part in this study. We thank the ARUP Institute for Clinical and Experimental Pathology (Salt Lake City, UT, USA) for supporting this project.

\section{References}

1 Legro RS, Kunselman AR, Dodson WC \& Dunaif A. Prevalence and predictors of risk for type 2 diabetes mellitus and impaired glucose tolerance in polycystic ovary syndrome: a prospective, controlled study in 254 affected women. Journal of Clinical Endocrinology and Metabolism 199984 165-169. (doi:10.1210/jcem.84.1.5393)

2 Wild RA, Carmina E, Diamanti-Kandarakis E, Dokras A, EscobarMorreale HF, Futterweit W, Lobo R, Norman RJ, Talbott E \& Dumesic DA. Assessment of cardiovascular risk and prevention of cardiovascular disease in women with the polycystic ovary syndrome: a consensus statement by the androgen excess and polycystic ovary syndrome (AE-PCOS) society. Journal of Clinical Endocrinology and Metabolism 201095 2038-2049. (doi:10.1210/jc.2009-2724)

3 Azziz R, Woods KS, Reyna R, Key TJ, Knochenhauer ES \& Yildiz BO. The prevalence and features of the polycystic ovary syndrome in an unselected population. Journal of Clinical Endocrinology and Metabolism 200489 2745-2749. (doi:10.1210/jc.2003-032046)

4 Franks S. Medical progress - polycystic-ovary-syndrome. New England Journal of Medicine 1995333 853-861. (doi:10.1056/NEJM199509 283331307)

5 Lauritsen MP, Bentzen JG, Pinborg A, Loft A, Forman JL, Thuesen LL, Cohen A, Hougaard DM \& Nyboe AA. The prevalence of polycystic ovary syndrome in a normal population according to the Rotterdam criteria versus revised criteria including anti-Mullerian hormone. Human Reproduction 201429 791-801. (doi:10.1093/humrep/det469)

6 Revised 2003 consensus on diagnostic criteria and long-term health risks related to polycystic ovary syndrome (PCOS). Human Reproduction 200419 41-47. (doi:10.1093/humrep/deh098)

7 Vink JM, Sadrzadeh S, Lambalk CB \& Boomsma DI. Heritability of polycystic ovary syndrome in a Dutch twin-family study. Journal of Clinical Endocrinology and Metabolism 200691 2100-2104. (doi:10.1210/ jc.2005-1494)

8 Barber TM \& Franks S. Genetics of polycystic ovary syndrome. Frontiers of Hormone Research 201340 28-39. (doi:10.1159/000341682)

9 Ewens KG, Stewart DR, Ankener W, Urbanek M, McAllister JM, Chen C, Baig KM, Parker SCJ, Margulies EH, Legro RS et al. Family-based analysis of candidate genes for polycystic ovary syndrome. Journal of Clinical Endocrinology and Metabolism 201095 2306-2315. (doi:10.1210/ jc.2009-2703)

10 Goodarzi MO. Looking for polycystic ovary syndrome genes: rational and best strategy. Seminars in Reproductive Medicine 200826 5-13. (doi:10.1055/s-2007-992919)

11 Urbanek M. The genetics of the polycystic ovary syndrome. Nature Clinical Practice. Endocrinology \& Metabolism 20073 103-111. (doi:10.1038/ncpendmet0400)

12 Legro RS, Driscoll D, Strauss JF, Fox J \& Dunaif A. Evidence for a genetic basis for hyperandrogenemia in polycystic ovary syndrome. PNAS 1998 95 14956-14960. (doi:10.1073/pnas.95.25.14956)

13 Abbott DH, Dumesic DA, Eisner JR, Colman RJ \& Kemnitz JW. Insights into the development of polycystic ovary syndrome (PCOS) from studies of prenatally androgenized female rhesus monkeys. Trends in endocrinology and metabolism 19989 62-67. (doi:10.1016/S10432760(98)00019-8)

14 Abbott DH \& Bird IM. Nonhuman primates as models for human adrenal androgen production: Function and dysfunction. Reviews in Endocrine \& Metabolic Disorders 200910 33-42. (doi:10.1007/ s11154-008-9099-8) 
15 Abbott DH, Nicol LE, Levine JE, Xu N, Goodarzi MO \& Dumesic DA. Nonhuman primate models of polycystic ovary syndrome. Molecular and Cellular Endocrinology 2013373 21-28. (doi:10.1016/ j.mce.2013.01.013)

16 Murray AA, Gosden RG, Allison V \& Spears N. Effect of androgens on the development of mouse follicles growing in vitro. Journal of Reproduction and Fertility 1998113 27-33. (doi:10.1530/jrf.0.1130027)

17 Vendola KA, Zhou J, Adesanya OO, Weil SJ \& Bondy CA. Androgens stimulate early stages of follicular growth in the primate ovary. Journal of Clinical Investigation 1998101 2622-2629. (doi:10.1172/ JCI2081)

18 Weil S, Vendola K, Zhou J \& Bondy CA. Androgen and folliclestimulating hormone interactions in primate ovarian follicle development. Journal of Clinical Endocrinology and Metabolism $1999 \mathbf{8 4}$ 2951-2956. (doi:10.1210/jcem.84.8.5929)

19 Tapp AL, Maybery MT \& Whitehouse AJO. Evaluating the twin testosterone transfer hypothesis: a review of the empirical evidence. Hormones and Behavior 201160 713-722. (doi:10.1016/j.yhbeh.2011. 08.011)

20 Lummaa V, Pettay JE \& Russell AF. Male twins reduce fitness of female co-twins in humans. PNAS 2007104 10915-10920. (doi:10.1073/pnas. 0605875104)

21 Medland SE, Loehlin JC, Willemsen G, Hatemi PK, Keller MC, Boomsma DI, Eaves LJ \& Martin NG. Males do not reduce the fitness of their female co-twins in contemporary samples. Twin Research and Human Genetics 200811 481-487. (doi:10.1375/twin.11.5.481)

22 Kuijper EAM, Vink JM, Lambalk CB \& Boomsma DI. Prevalence of polycystic ovary syndrome in women from opposite-sex twin pairs. Journal of Clinical Endocrinology and Metabolism 200994 1987-1990. (doi:10.1210/jc.2009-0191)

23 Dumesic DA, Goodarzi MO, Chazenbalk GD \& Abbott DH. Intrauterine environment and polycystic ovary syndrome. Seminars in Reproductive Medicine 201432 159-165. (doi:10.1055/s-0034-1371087)

24 Cole B, Hensinger K, Maciel GAR, Chang RJ \& Erickson GF. Human fetal ovary development involves the spatiotemporal expression of P450c17 protein. Journal of Clinical Endocrinology and Metabolism 200691 3654-3661. (doi:10.1210/jc.2006-0641)

25 Zhou R, Bird IM, Dumesic DA \& Abbott DH. Adrenal hyperandrogenism is induced by fetal androgen excess in a rhesus monkey model of polycystic ovary syndrome. Journal of Clinical Endocrinology and Metabolism 200590 6630-6637. (doi:10.1210/jc.2005-0691)

26 Beckpeccoz P, Padmanabhan V, Baggiani AM, Cortelazzi D, Buscaglia M, Medri G, Marconi AM, Pardi G \& Beitins IZ. Maturation of hypothalamic-pituitary-gonadal function in normal human fetuses circulating levels of gonadotropins, their common $\alpha$-subunit and free testosterone, and discrepancy between immunological and biologicalactivities of circulating follicle-stimulating-hormone. Journal of Clinical Endocrinology and Metabolism 199173 525-532. (doi:10.1210/jcem73-3-525)

27 Kuijper EAM, Twisk JWR, Korsen T, Caanen MR, Kushnir MM, Rockwood AL, Meikle AW, Hompes PG, Wit JM \& Lambalk CB. Mid-pregnancy, perinatal and neonatal reproductive endocrinology, a prospective cohort study in twins and singleton controls. Accepted for publication in. Fertility and Sterility 2016. In press. (doi:10.1016/ j.fertnstert.2015.08.016)

28 Hatch R, Rosenfield RL, Kim MH \& Tredway D. Hirsutism implications, etiology, and management. American Journal of Obstetrics and Gynecology 1981140 815-830.

29 Kushnir MM, Rockwood AL, Bergquist J, Varshavsky M, Roberts WL, Yue BF, Bunker AM \& Meikle AW. High-sensitivity tandem mass spectrometry assay for serum estrone and estradiol. American Journal of Clinical Pathology 2008129 530-539. (doi:10.1309/ LC03BHQ5XJPJYEKG)

30 Kushnir MM, Rockwood AL \& Bergquist J. Liquid chromatographytandem mass spectrometry applications in endocrinology. Mass Spectrometry Reviews 201029 480-502. (doi:10.1002/mas.20264)
31 Kushnir MM, Blamires T, Rockwood AL, Roberts WL, Yue BF, Erdogan E, Bunker AM \& Meikle AW. Liquid chromatography-tandem mass spectrometry assay for androstenedione, dehydroepiandrosterone, and testosterone with pediatric and adult reference intervals. Clinical Chemistry 201056 1138-1147. (doi:10.1373/clinchem.2010.143222)

32 Kushnir MM, Rockwood AL, Yue B \& Meikle AW. High sensitivity measurement of estrone and estradiol in serum and plasma using LC-MS/MS. Methods in Molecular Biology 2010603 219-228. (doi:10.1007/978-1-60761-459-3_20)

33 Kushnir MM, Rockwood AL, Nelson GJ, Yue BF \& Urry FM. Assessing analytical specificity in quantitative analysis using tandem mass spectrometry. Clinical Biochemistry 200538 319-327. (doi:10.1016/ j.clinbiochem.2004.12.003)

34 Abbott DH, Dumesic DA \& Franks S. Developmental origin of polycystic ovary syndrome - a hypothesis. Journal of Endocrinology 2002 174 1-5. (doi:10.1677/joe.0.1740001)

35 Padmanabhan V \& Veiga-Lopez A. Developmental origin of reproductive and metabolic dysfunctions: androgenic versus estrogenic reprogramming. Seminars in Reproductive Medicine 201129 173-186. (doi:10.1055/s-0031-1275519)

36 Walters KA, Allan CM \& Handelsman DJ. Rodent models for human polycystic ovary syndrome. Biology of Reproduction 201286 article 149, 1-12. (doi:10.1095/biolreprod.111.097808)

37 Abbott DH, Barnett DK, Levine JE, Padmanabhan V, Dumesic DA, Jacoris S \& Tarantal AF. Endocrine antecedents of polycystic ovary syndrome in fetal and infant prenatally androgenized female rhesus monkeys. Biology of Reproduction 200879 154-163. (doi:10.1095/ biolreprod.108.067702)

38 Hague WM, Adams J, Rodda C, Brook CGD, Debruyn R, Grant DB \& Jacobs HS. The prevalence of polycystic ovaries in patients with congenital adrenal-hyperplasia and their close relatives. Clinical Endocrinology 199033 501-510. (doi:10.1111/j.1365-2265.1990.tb03887.x)

39 Futterweit W \& Deligdisch L. Histopathological effects of exogenously administered testosterone in 19 female to male-transsexuals. Journal of Clinical Endocrinology and Metabolism 198662 16-21. (doi:10.1210/ jcem-62-1-16)

40 Ikeda K, Baba T, Noguchi H, Nagasawa K, Endo T, Kiya T \& Saito T. Excessive androgen exposure in female-to-male transsexual persons of reproductive age induces hyperplasia of the ovarian cortex and stroma but not polycystic ovary morphology. Human Reproduction 201328 453-461. (doi:10.1093/humrep/des385)

41 Pache TD, Chadha S, Gooren LJG, Hop WCJ, Jaarsma KW, Dommerholt HB \& Fauser BC. Ovarian morphology in long-term androgen-treated female to male-transsexuals - a human-model for the study of polycystic ovarian syndrome. Histopathology 199119 445-452. (doi:10.1111/j.1365-2559.1991.tb00235.x)

42 Spinder T, Spijkstra JJ, Vandentweel JG, Burger CW, Vankessel H, Hompes PGA \& Gooren LJG. The effects of long-term testosterone administration on pulsatile luteinizing-hormone secretion and on ovarian histology in eugonadal female to male-transsexual subjects. Journal of Clinical Endocrinology and Metabolism 198969 151-157. (doi:10.1210/jcem-69-1-151)

43 Anderson H, Fogel N, Grebe SK, Singh RJ, Taylor RL \& Dunaif A. Infants of women with polycystic ovary syndrome have lower cord blood androstenedione and estradiol levels. Journal of Clinical Endocrinology and Metabolism 201095 2180-2186. (doi:10.1210/jc.2009-2651)

44 Hickey M, Sloboda DM, Atkinson HC, Doherty DA, Franks S, Norman RJ, Newnham JP \& Hart R. The relationship between maternal and umbilical cord androgen levels and polycystic ovary syndrome in adolescence: a prospective cohort study. Journal of Clinical Endocrinology and Metabolism 200994 3714-3720. (doi:10.1210/jc.2009-0544)

45 Maliqueo M, Lara HE, Sanchez F, Echiburu B, Crisosto N \& Sir-Petermann T. Placental steroidogenesis in pregnant women with polycystic ovary syndrome. European Journal of Obstetrics, Gynecology, and Reproductive Biology 2013166 151-155. (doi:10.1016/ j.ejogrb.2012.10.015) 
46 Boutzios G, Livadas S, Piperi C, Vitoratos N, Adamopoulos C, Hassiakos D, Iavazzo C \& Diamanti-Kandarakis E. Polycystic ovary syndrome offspring display increased oxidative stress markers comparable to gestational diabetes offspring. Fertility and Sterility 201399 943-950. (doi:10.1016/j.fertnstert.2012.10.050)

47 Barry JA, Kay AR, Navaratnarajah R, Iqbal S, Bamfo JEAK, David AL, Hines $\mathrm{M} \&$ Hardiman PJ. Umbilical vein testosterone in female infants born to mothers with polycystic ovary syndrome is elevated to male levels. Journal of Obstetrics and Gynaecology 201030 444-446. (doi:10.3109/01443615.2010.485254)

48 Kragie L. Aromatase in primate pregnancy: a review. Endocrine Research 200228 121-128. (doi:10.1081/ERC-120015041)

49 Berg FD \& Kuss E. Serum concentration and urinary-excretion of classical estrogens, catecholestrogens and 2-methoxyestrogens in normal human-pregnancy. Archives of Gynecology and Obstetrics 1992 251 17-27. (doi:10.1007/BF02718274)

50 Troisi R, Potischman N, Roberts J, Siiteri P, Daftary A, Sims C \& Hoover RN. Associations of maternal and umbilical cord hormone concentrations with maternal, gestational and neonatal factors (United States). Cancer Causes \& Control 200314 347-355. (doi:10.1023/ A:1023934518975)

51 Troisi R, Potischman N, Johnson CN, Roberts JM, Lykins D, Harger G, Markovic N, Siiteri P \& Hoover RN. Estrogen and androgen concentrations are not lower in the umbilical cord serum of pre-eclamptic pregnancies. Cancer Epidemiology, Biomarkers \& Prevention 200312 $1268-1270$.

52 Troisi R, Potischman N, Roberts JM, Harger G, Markovic N, Cole B, Lykins D, Siiteri P \& Hoover RN. Correlation of serum hormone concentrations in maternal and umbilical cord samples. Cancer Epidemiology, Biomarkers \& Prevention 200312 452-456.

53 Cohen-Bendahan CCC, van de Beek C \& Berenbaum SA. Prenatal sex hormone effects on child and adult sex-typed behavior: methods and findings. Neuroscience and Biobehavioral Reviews 200529 353-384. (doi:10.1016/j.neubiorev.2004.11.004)
54 Speroff L and Fritz MA. Clinical Gynecologic Endocrinology \& Infertility (8th edition), Lippincott Williams \& Wilkins, 2012.

55 Hill M, Parizek A, Kancheva R, Duskova M, Velikova M, Kriz L, Klimkova M, Paskova A, Zizka Z, Matucha P et al. Steroid metabolome in plasma from the umbilical artery, umbilical vein, maternal cubital vein and in amniotic fluid in normal and preterm labor. Journal of Steroid Biochemistry and Molecular Biology 2010121 594-610. (doi:10.1016/ j.jsbmb.2009.10.012)

56 Laatikainen T, Pelkonen J, Apter D \& Ranta T. Fetal and maternal serum levels of steroid sulfates, unconjugated steroids, and prolactin at term pregnancy and in early spontaneous labor. Journal of Clinical Endocrinology and Metabolism 198050 489-494. (doi:10.1210/ jcem-50-3-489)

57 Paskova A, Parizek A, Hill M, Velikova M, Kubatova J, Duskova M, Adamcova K, Koucky M, Simjak P, Cerny A et al. Steroid metabolome in the umbilical cord: is it necessary to differentiate between arterial and venous blood? Physiological Research 201463 115-126.

58 Lee JS, Ettinger B, Stanczyk FZ, Vittinghoff E, Hanes V, Cauley JA, Chandler W, Settlage J, Beattie MS, Folkerd E et al. Comparison of methods to measure low serum estradiol levels in postmenopausal women. Journal of Clinical Endocrinology and Metabolism 200691 3791-3797. (doi:10.1210/jc.2005-2378)

59 Rosner W, Auchus RJ, Azziz R, Sluss PM \& Raff H. Position statement: utility, limitations, and pitfalls in measuring testosterone: an endocrine society position statement. Journal of Clinical Endocrinology and Metabolism 200792 405-413. (doi:10.1210/jc.2006-1864)

60 Taieb J, Benattar C, Birr AS \& Lindenbaum A. Limitations of steroid determination by direct immunoassay. Clinical Chemistry $2002 \mathbf{4 8}$ 583-585.

61 Taieb J, Mathian B, Millot F, Patricot MC, Mathieu E, Queyrel N, Lacroix I, Somma-Delpero C \& Boudou P. Testosterone measured by 10 immunoassays and by isotope-dilution gas chromatography-mass spectrometry in sera from 116 men, women, and children. Clinical Chemistry 200349 1381-1395. (doi:10.1373/49.8.1381)

Received 11 July 2015

Revised version received 9 September 2015

Accepted 1 October 2015 